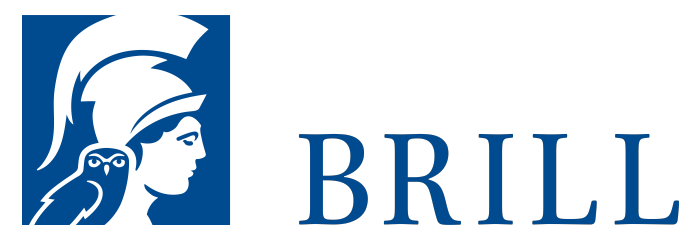

\title{
Inszenierte Alterität
}

Zigeunerfiguren in Literatur, Oper und Film

Author: Kirsten von Hagen

Nomadisierend, ohne Heimat und Herkunft, verbunden mit der Vorstellung des Ungeordneten, bezeichnet die 'Zigeunerin' zugleich ein poetisches Ideal zahlreicher Autoren des 19. und 2o. Jahrhunderts. Mit klar definierbaren Stereotypen, die häufig mythemischen Charakter haben, werden Zigeunerfiguren in der Literatur, aber auch in Oper und Film, inszeniert und in ihrer Alterität festgeschrieben. Das 19. Jahrhundert ist in besonderer Weise von einem ambivalenten Umgang mit dem als exotisch empfundenen Anderen gekennzeichnet. Die Zigeunerin ist die zugleich ein- wie ausgeschlossene Dritte, eine hybride Figur, die immer neue Bedeutungen generiert und besonders in Umbruchsituationen zu finden ist.

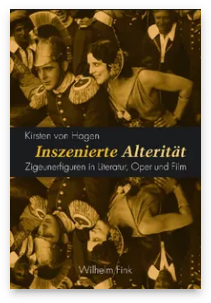

Pages: 238

Seiten, $5 \mathrm{~s} / \mathrm{w}$

Abb.

Language:

German

Subjects:

General,

Literature and

Cultural Studies

Publisher: Brill |

Fink

E-Book (PDF)

Released online:

og Dec 2019

ISBN: 978-3-

8467-4714-8

List price

USD $\$ 30.00$

Paperback

Publication date:

18 Feb 2009

ISBN: 978-3-

7705-4714-2

List price

USD $\$ 30.00$ 
For more information see brill.com

Order information: Order online at brill.com +44330 333 0049 | customerservices@brill.com Submission information: brill.com/authors

Titles published by Brill | Fink, Brill | mentis or Brill | Schöningh: +49(o)715413279216| brill@brocom.de 